Induced magnetic field used to detect the sigma phase of a 2205 duplex

\title{
stainless steel
}

Edgard de Macedo Silva ${ }^{1}$, Josinaldo Pereira Leite ${ }^{2}$, João Pereira Leite ${ }^{3}$, Walter Macedo Lins Fialho ${ }^{1}$, Victor Hugo C. de Albuquerque ${ }^{4}$, João Manuel R. S. Tavares ${ }^{5}$

${ }^{1}$ Instituto Federal de Educação Ciência e Tecnologia da Paraíba, Av. Primeiro de Maio, 720 - Jaguaribe, João Pessoa - PB, 58015-435, Brazil. Email: edgard@ifpb.edu.br, wmlfialho@gmail.com

${ }^{2}$ Universidade Federal da Paraíba, Jardim Universitário, s/n - Castelo Branco, João Pessoa - PB, 58051-900, Brazil. Email: josinaldo@ct.ufpb.edu.br

${ }^{3}$ Universidade Federal de Campina Grande, R. Aprígio Veloso, 882 Universitário, Campina Grande - PB, 58429-900, Brazil. Email: joao.leite100@yahoo.com.br

${ }^{4}$ Programa de Pós-Graduação em Informática Aplicada, Universidade de Fortaleza, Fortaleza, Ceará, Brazil. Email: victor.albuquerque@unifor.br 
${ }^{5}$ Instituto de Ciência e Inovação em Engenharia Mecânica e Engenharia Industrial, Departamento de Engenharia Mecânica, Faculdade de Engenharia, Universidade do Porto, Porto, Portugal, Rua Dr. Roberto Frias, S/N - 4200-465 Porto, Portugal. Email: tavares@,fe.up.pt

\section{Corresponding author:}

Prof. João Manuel R. S. Tavares

Faculdade de Engenharia da Universidade do Porto

Rua Dr. Roberto Frias, $\mathrm{s} / \mathrm{n}$

4200-465 Porto, PORTUGAL

email: tavares@fe.up.pt

Phone: +351 22 5081487, Fax: +351 22 5081445, url:

www.fe.up.pt/ tavares 


\title{
Induced magnetic field used to detect the sigma phase of a 2205 duplex stainless steel
}

\begin{abstract}
Sigma phases are formed due to heat treatments and/or welding processes during the solidification stage, and they are responsible for embrittlement of duplex stainless steels. Only a small amount of this phase promotes unfavorable mechanical properties and liability to corrosion. In this work, a new affordable approach to detect and follow-up the kinetics of the sigma phase transformation is evaluated. The measurements are based on an induced magnetic field generated through the interaction between an external magnetic field and the microstructure under study. To validate this approach, the induced magnetic field values are compared with the values of the Charpy impact energy, and the sigma phase is assessed by optical microscopy. Moreover, surface fractures are analyzed by scanning electron microscopy and X-ray diffraction. The results from the 2205 duplex stainless steel used show that there is a direct relation among the impact energy, fracture mechanism and induced magnetic field. The method proved to be able to follow up the embrittlement of the DSS successfully. Moreover, the results confirm that the presence of a sigma phase can be studied based on
\end{abstract}


an induced magnetic field, even when in low amounts, and that a critical threshold value can be defined to monitor structures in service.

Keywords: Non-destructive testing; Optical microscopy; Charpy test; Scanning electron microscopy; Sigma phase; X-ray diffraction. 


\section{Introduction}

Duplex stainless steels (DSS) hold important properties of both the facecentered cubic (austenitic) and body-centered cubic (ferritic) phases in their microstructures. The ferrite and austenite phases are present in roughly equal volume fractions $[1,2]$. Consequently, DSS have excellent strength and toughness, improved corrosion resistance (especially to localized corrosion) and exceptional resistance to halide stress-corrosion cracking [3, 4]. Due to these excellent properties, DSS are widely used in the marine and petrochemical industries, as well as for desalination services and in paper mills [5-7].

However, when these steels are heated above $600{ }^{\circ} \mathrm{C}$, the formation of the brittle and non-magnetic sigma $(\sigma)$ phase occurs [8-10]. This phase presents high hardness (around $900 \mathrm{HV}$ ) and is a phase rich in chromium. Also the sigma phase, which is usually formed from the ferrite phase, reduces the impact toughness and the resistance to localized corrosion due to the adjacent zones that become depleted of $\mathrm{Cr}$ and Mo [11-14]. Small amounts (4\%) of the sigma phase are able to compromise the material toughness $[6,9,15]$. Even these low quantities promote a considerable decrease of toughness without any notable influence on the hardness. For instance, the precipitation of $1.3 \%$ of this phase decreased the impact toughness from $320 \mathrm{~J}$ (solute treated) to $24 \mathrm{~J}$ (aged samples at $800{ }^{\circ} \mathrm{C}$ for $10 \mathrm{~min}$ ) $[6,9,16]$. The sigma 
phase forms after aging at temperatures between 600 and $950{ }^{\circ} \mathrm{C}$ and after cooling from temperatures above $900{ }^{\circ} \mathrm{C}$, as occurs in the heat-affected zone during welding. Appropriate toughness properties are achieved by applying proper annealing temperatures and cooling rates, which explains why the toughness properties in DSS are in general satisfactory $[17,18]$.

The ferrite phase is ferromagnetic while the austenite and sigma phase are paramagnetic. Therefore, magnetic-based testing approaches can be used for testing duplex stainless steels, since these tests are sensitive to the presence and amount of the ferromagnetic ferrite phase. Mohapatra et al. $[19,20]$ showed that the remanence measurement of the magnetic hysteresis loop is able to follow the formation of the $\sigma$ phase even when presented in low volume fractions. Structure-sensitive magnetic properties like coercivity and remanence are affected by microstructural modifications. Therefore, considerable attention has been given to magnetic techniques to study ferromagnetic materials.

Previous works have also shown the applicability of magnetic-based measurements to detect ferritic phase decomposition and the presence of the sigma phase in duplex stainless steels [9, 21-23]. Magnetic susceptibility tests have been applied on samples with different levels of ferritic phase decomposition, and a decreasing of the magnetic susceptibility was observed as the time of thermal aging increased due to the formation of the sigma 
phase. The non-magnetic sigma phase reduces the magnetic field permeability of the materials and therefore also the magnetic susceptibility of such materials [21,22].

Other traditional non-destructive tests that have been used to characterize material microstructures are based on eddy current testing (ECT) [23-25], ultrasound [26-30] and magnetic Barkhausen noise [8, 31, 32], which have also been used to detect the sigma phase [8, 23-26]. For example, Normando et al., in [8], studied the sigma phase transformation in samples aged at 800 and $900{ }^{\circ} \mathrm{C}$ for times up to 2 hours using the eddy current technique. The authors observed that the impedance decreases as the heat treatment time increases. These authors noted a sharp decreasing in impedance in the first 15 min, which was not associated to sigma phase precipitation. Instead, the authors associated this behavior to some second austenite phase precipitation and also to a very sharp softening that was detected in the same time interval. A considerable decrease of impedance observed after $15 \mathrm{~min}$ is said to be due to the paramagnetic sigma phase precipitation.

Camerini et al., in [24], evaluated conventional electromagnetic (ECT) and saturated low frequency eddy current (SLOFEC) techniques to characterize super duplex stainless steel samples. SLOFEC differs from ECT because it uses an external DC magnetic field that reaches the magnetic saturation of the sample under study. The depth penetration of the eddy 
current field lines is increased once the local relative permeability is decreased by the DC magnetization. This is attractive as it means that larger volumes of materials can be analyzed due to the greater penetration of the eddy current. Both techniques were able to evaluate the presence of the sigma phase and to estimate the $\delta$ ferrite content. Other works discussed the advantages of using the eddy current technique for the characterization of different materials [33-35]; however, neither of these latter two studies presented the potential to characterize the sigma phase when it was in low amounts in SDSS, nor did they correlate the electromagnetic results to the $\delta$ content. However, a limitation of these two studies was the low number of samples tested which could jeopardize their results.

Ultrasound testing has also been used to detect the sigma phase transformation in duplex stainless steels $[8,26-30,36]$. For example, Normando et al., $[8,26]$ analyzed the influence of the sound velocity to follow-up the $\sigma$ phase formation at temperatures of 800 and $900{ }^{\circ} \mathrm{C}$ for times up to $2 \mathrm{~h}$. The results showed that ultrasonic velocity increases with longer times of heat treatment. The sound velocity is influenced by the material density and the elastic modulus [37], therefore the changes observed for the sound velocity indicate changes of the material properties due to the generation of the sigma phase from the ferrite phase. The results also showed that the sound velocity measurements are more precise for aging times above 
30 min $[8,26]$. Silva et al. $[27,28]$ applied ultrasound to microstructure characterization. These authors studied the ferrite decomposition at temperatures of 425 and $475{ }^{\circ} \mathrm{C}$ and showed that the changes of the sound speed measurements are directly proportional to the variation of the material hardness, presenting sensitivity to the phase transformations. Thus, the sound speed is an important nondestructive parameter to follow-up the hardening kinetics of duplex stainless steels.

In this study, induced magnetic field measurements obtained in the reversibility region of magnetic domains were used to follow the formation of the undesirable sigma phase. Samples of the 2205 duplex stainless steel were aged in order to obtain different amounts of the sigma phase up to $18 \%$. The aim was to compare this approach with others like the ones based on ultrasound and eddy currents, when applied to regions containing low amounts of the sigma phase of the duplex stainless steel under study. The toughness of these samples had already been reduced due to the presence of the sigma phase. The proposed approach revealed to be promising to follow the decomposition of small particles of ferrite at temperatures below $550{ }^{\circ} \mathrm{C}$ for SAF 2205 duplex stainless steels [36] and this approach was used here to evaluate the sigma phase. The findings obtained show that the proposed approach has an interval of error of around $2 \times 10^{-5}$ tesla considering an error of $5 \%$. In order to verify the dispersion of the signals acquired due to 
external noise. The presence of data outliers and their influence on the results were also analyzed.

\section{Experimental procedures}

Samples of a 2205 DSS were thermally aged in an electric resistance furnace at temperatures of $700,750,800,850,900$ and $1000{ }^{\circ} \mathrm{C}$ for times of $0.25,1$ and 2 hours, Table 1 . The samples were prepared by mechanical polishing and electrolytic etching in a $10 \% \mathrm{KOH}$ solution with a voltage of $3 \mathrm{~V}$ for 15 $\mathrm{s}$, which reveals mainly the sigma phase. The amount of the sigma phase was quantified in microstructural images acquired by optical microscopy (NIKON FX 35XD Optic Microscopy). The amount, i.e., the volumetric fraction, of the sigma phase was calculated using a computational tool of image processing and analysis that includes an artificial neural network to detect and characterize microstructures [38-43]. Forty images were analyzed and the volume fraction determined considering a $95 \%$ confidence interval with a maximum error of $5 \%$. The Charpy impact test was performed on the samples subjected to the same treatments; the samples were $10 \times 5 \times 55 \mathrm{~mm}^{3}$. Five samples were used for each time and the temperatures of 800 and 900 ${ }^{\circ} \mathrm{C}$ were particularly studied because the amount of the sigma phase needed to embrittle the material $(4 \%)$ is reached faster due to the kinetics of the 
formation associated to these high temperatures. The surface microstructures of the as-received samples and the samples aged at 800 and $900{ }^{\circ} \mathrm{C}$ were analyzed via scanning electron microscopy (SEM) for fractures.

The formation of the sigma phases were studied using X-ray diffraction tests with an X-ray Diffractometer from Shimadzu Corporation (Japan), model XRD-6000 vertical type, with Cuk- $\alpha$ radiation. The scanning angle varied from 41 to $53^{\circ}$ with steps of $0.02^{\circ}$.

Figure 1 shows the experimental setup of the proposed approach to study the samples based on the application and assessment of induced fields. In this setup, a solenoid (with $N / L=21.26 \mathrm{~m}^{-1}$, where $N$ is the number of closely spaced turns and $L$ the length) is responsible for generating the external magnetic field, and a Hall Effect sensor (from Honeywell, USA, model SS495A, with sensitivity of $3.125 \pm 0.125 \mathrm{mV} / \mathrm{G}$ ) is used to determine the induced magnetic field. External magnetic fields up to $282 \mathrm{~A} / \mathrm{m}$ were applied in order to generate the induced fields in the region of reversible domain wall motion, leaving no permanent magnetization in the sample under test. This region corresponds to the region of the magnetization curve where the domains are randomly oriented, and the application of an external magnetic field does not cause their permanent motion or residual field and therefore, the demagnetization of the material is unnecessary [44, 45]. A microscopy 
analysis of the presence of the irreversible domain motion was not part of this work, however, no macro effect of this kind was observed in the measurements.

The induced magnetic field in the reversibility region is proportional to the magnetic permeability of the material under study. This means that the induced magnetic field obtained by a fixed external magnetic field is not affected by changes in terms of the geometry of the samples. The correlation of the induced field with the amount of the sigma phase is related to the reduction of the induced magnetic field that corresponds to the presence of embrittlement. The ideal external field was considered as the highest difference found between the induced magnetic fields of the samples treated for 2 hours and the as-received state sample. Five hundred signals were acquired from each sample.

\section{Results and Discussion}

The toughness of duplex stainless steels, when submitted to thermal cycling at temperatures above $600{ }^{\circ} \mathrm{C}$, is affected by the formation of the paramagnetic sigma phase. Figure 2 shows the microstructures of the thermally aged samples at 800 and $900{ }^{\circ} \mathrm{C}$ for 2 hours and their X-ray diffraction patterns. This Figure shows a higher amount of precipitates at 900 
${ }^{\circ} \mathrm{C}$. At $800{ }^{\circ} \mathrm{C}$, the microstructure shows the sigma $(\sigma)$ phase formed from the ferrite $(\delta)$ phase, as well as the reaction of the $\sigma+$ austenite $\left(\gamma_{2}\right)$ phases. This reaction is noticeable because the electrolytic etching in a $10 \% \mathrm{KOH}$ solution attacked the sigma phases and the spaces between them, which are composed of the $\gamma_{2}$ phase, were not attacked and a discontinuous precipitation is involved. The sigma phase precipitates from ferrite in the $\gamma / \delta$ interfaces or in the $\gamma / \delta$ grain boundaries. For most aging temperatures, ferrite decomposes into $\gamma_{2}$ and $\sigma$ phases via an eutectoid reaction. A small percentage of the Chi $(\chi)$ phase is also precipitated in duplex and super duplex steels from ferrite when the aging temperature is between 700 and $900{ }^{\circ} \mathrm{C}[46]$.

The precipitation of the $\sigma, \gamma_{2}$ and $\chi$ phases, which are paramagnetic phases, reduces the magnetic properties of the steel as the ferrite phase is ferromagnetic and decomposes into these phases. Magnetic susceptibility has been used to study the decomposition of the ferrite phase in duplex stainless steels at temperatures ranging from 350 to $900{ }^{\circ} \mathrm{C}[21,22]$. For these temperatures the magnetic susceptibility drops rapidly at the beginning and then stabilizes. For temperatures up to $550{ }^{\circ} \mathrm{C}$, ferrite decomposes via spinodal decomposition, and from 600 to $900{ }^{\circ} \mathrm{C}$, the magnetic susceptibility decreases because of the presence of the sigma phase. Another magnetic technique used to follow the ferrite decomposition is based on an induced 
magnetic field generated from the interaction between an applied external field and the microstructure [36]. This technique uses induced fields in the reversibility region of magnetic domains. The magnetic permeability was used to follow the ferrite decomposition at temperatures above $550{ }^{\circ} \mathrm{C}$ and the results were similar [36].

Figure 3 presents the difference, which is called amplitude measurement, among the induced magnetic fields for the samples aged for 2 hours and the as-received duplex stainless steel against the applied external fields. The amplitude compares a sample with the sigma phase against a sample without the sigma phase. The Figure demonstrates that the values increase up to a maximum peak of $211.5 \mathrm{~A} / \mathrm{m}$, after which they decrease. Higher induced magnetic field lines detect the random distributed sigma phases more easily as the external field increases. The last decrease of amplitude shown in Figure 3 was due to the beginning of the saturation of the Hall sensor used. Figure 3 also indicates that $211.5 \mathrm{~A} / \mathrm{m}$ is the ideal value to apply the external field in order to discriminate the amplitudes more clearly.

Figure 3 also shows the effect of the temperature on the formation of the sigma phase. The use of the ideal field revealed that the samples aged at temperatures of 700 and $1000{ }^{\circ} \mathrm{C}$ presented lower amounts of the sigma phase compared to the ones aged at 800 and $900{ }^{\circ} \mathrm{C}$. Camerini et al, in [24], observed that thermal aging for 1 hour at $1220{ }^{\circ} \mathrm{C}$ does not lead to sigma 
phase formation and that at $1000{ }^{\circ} \mathrm{C}$ generates only $3.4 \%$ of the sigma phase. In this work, the samples thermally aged at $900{ }^{\circ} \mathrm{C}$ for 2 hours presented $17.87 \%$ of this phase.

Figure 4 shows the values of the induced magnetic fields (B) against time and temperature with an applied external field of $211.5 \mathrm{~A} / \mathrm{m}$. The induced magnetic field decreases due to the presence of the paramagnetic sigma phase and the highest rate of precipitation occurs at $850{ }^{\circ} \mathrm{C}$. Normally, most of the thermally aged steels at 800 and $900{ }^{\circ} \mathrm{C}$ present higher rates of sigma phase precipitation than other temperature below 800 or above $900{ }^{\circ} \mathrm{C}[9$, 10]. Other techniques, such as the ones based on ultrasound $[8,26]$ and eddy currents $[8,24]$, have also been used to detect the sigma phase in duplex stainless steels. Both techniques can detect the presence of this phase for aging times over $0.5 \mathrm{~h}$, while the proposed approach based on induced magnetic field can also be used for times below $0.5 \mathrm{~h}$. This greater range of the proposed approach is very relevant since a thermal aging treatment at 800 ${ }^{\circ} \mathrm{C}$ for $0.5 \mathrm{~h}$ is able to reduce the material toughness by up to $65 \%$ [9]. Thermal aging at 700,750 and $1000{ }^{\circ} \mathrm{C}$ did not affect the toughness of the studied material due to the low content of the sigma phase. A value of $2.28 \%$ of the sigma phase was found for $800{ }^{\circ} \mathrm{C}$ for $0.25 \mathrm{~h}$, which corresponds to the level of the induced magnetic field associated to these temperatures, as can be seen in Figure 4. 
Figure 5 shows the absorbed impact energy in function of the induced field for the samples aged at 800 and $900{ }^{\circ} \mathrm{C}$ and times up to 2 hours. As already reported $[9,10]$, the thermal aging at 800 and $900{ }^{\circ} \mathrm{C}$ presented the highest rates of sigma phase precipitation. Figure 5 demonstrates that the induced magnetic field is able to follow the embrittlement process of the analyzed steel. The aged sample at $800{ }^{\circ} \mathrm{C}$ for $1 \mathrm{~h}$ presented a decrease of around $82 \%$ in terms of toughness. Sigma phases greater than $4 \%$ reduce the impact strength of the steel by $70 \%$ [47]. According to Fargas et al., [47], as the precipitation of the sigma phase increases, cracks occur preferentially in the contours of the particles of this phase that are oriented in the rolling direction. Thermal aging at temperatures of 800 and $900{ }^{\circ} \mathrm{C}$ for $0.25 \mathrm{~h}$ generate losses in toughness of 31.3 and $54.5 \%$, respectively. Hence, in order to monitor duplex stainless steel structures, it is important to assess their microstructure even for times inferior to $0.5 \mathrm{~h}$.

Figure 6 shows the fractured surfaces obtained by SEM of the samples aged at 800 and $900{ }^{\circ} \mathrm{C}$ for $0.25 \mathrm{~h}$. A change in the fracture mechanism from ductile to brittle is apparent in this Figure. For the $800{ }^{\circ} \mathrm{C}$ sample the microstructure shows a ductile fracture mode with a large number of deep dimples visible, and with some cracks already perceptible due to the presence of the sigma phase. These cracks are even more noticeable in the $900{ }^{\circ} \mathrm{C}$ sample. 
The variations of the induced magnetic field and the impact energy in function of the amount of the sigma phase are presented in Figure 7. Here the absorbed energy decreases rapidly and tends to a plateau as the material becomes brittle. Small amounts of sigma phase promote a significant decrease in toughness: $3 \%$ causes a reduction of $78 \%$ in the absorption of the impact energy. The correlation between this phase and the impact energy has already been reported $[9,48]$.

Figure 7 also shows that the induced magnetic field follows the formation of the sigma phase and that there is a critical value that corresponds to the brittle condition of the material. This can be a useful tool to monitor structures in service, since it can detect the presence of the sigma phase even when in low amounts. As previously mentioned, other techniques like the ones based on eddy currents and ultrasound are not so precise for short aging times of around $0.25 \mathrm{~h}$ at temperatures of 800 and $900{ }^{\circ} \mathrm{C}[8,26]$.

Based on the experimental findings, the measurement of induced magnetic fields can be used to detect, in service, material embrittlement due to the sigma phase. For example, welded joints can be tested by performing analysis before the welding, or in regions distance from the welded regions, and after the welding; and, if the reduction in the induced magnetic field corresponds to a content of $4 \%$ of sigma phase, then it should be interpreted 
as this result is a strong indication that the structure under analysis needs to be repaired.

Within the scope of this work, an outlier analysis was also performed on the values obtained for the induced field. Twenty-two external fields were applied for each aging condition until the saturation of the Hall sensor. Outliers were only found in the data acquired for the samples aged at $800{ }^{\circ} \mathrm{C}$ for $2 \mathrm{~h}$ with an applied external field of $102.01 \mathrm{~A} / \mathrm{m}$ and at $900{ }^{\circ} \mathrm{C}$ for $2 \mathrm{~h}$ with an applied external field of $133.26 \mathrm{~A} / \mathrm{m}$, as shown in Figure 8. In the first case, the outlier is not considered a new value as it is stills inside the error bar. In the second case, the outliner is outside the error bar, but the difference was not enough to affect the results obtained. These results therefore demonstrate that the proposed approach to test for the sigma phase is accurate and robust.

\section{Conclusions}

Embrittlement in a 2205 duplex stainless steel due to the presence of the sigma phase was studied in this work. The phase was detected based on an induced magnetic field that was generated by the interaction of an external magnetic field and the microstructure under analysis. 
The findings obtained in the various tests executed conclude the following: (1) There is an ideal external magnetic field that should be applied in order to obtain the best amplitude for the phase assessment. In the present work, a value of $211.5 \mathrm{~A} / \mathrm{m}$ was used as the ideal field. (2) The presence of the paramagnetic sigma phase reduces the induced magnetic field even when the phase is in reduced quantities. Other testing techniques such as the ones based on eddy currents and ultrasound have assessment limits of $0.25 \mathrm{~h}$ for temperatures above $800{ }^{\circ} \mathrm{C}$. (3) The induced magnetic field is directly proportional to the absorbed energy. Based on the experimental findings, we can conclude that the induced magnetic field can be used to continually monitor in-service structures that are susceptible to embrittlement. The method can follow the presence of low amounts of the sigma phase, which cannot be easily detected by the common non-destructive testing techniques. However, low sigma phases are enough to promote significant reductions in toughness. (4) The induced magnetic field in the region of reversibility of magnetic domain is directly proportional to the material permeability and this means that the induced magnetic field obtained by the ideal external magnetic field is not affected by changes in the geometry of the samples. (5) Additionally, in comparison to other non-destructive testing techniques, another attractive characteristic of this technique is the ease of use and 
interpretation, besides being more affordable than ultrasound testing, for example.

To conclude, the testing approach proposed can predict accurately and efficiently the best moment to carry out maintenance services, which leads to reduced costs and maintenance time.

As to future work, we intend to use computational classifiers in order to identify the material phases based on the data collected by the proposed testing approach. Other interesting works could be studies about the flux density within the samples under study considering the thickness of the samples and the applied magnetic fields.

\section{Acknowledgments}

The sponsorship from the Coordination for the Improvement of Higher Education Personnel (CAPES), in Brazil, through the scholarship process BEX $2634 / 15-5$ at Faculdade de Engenharia da Universidade do Porto (FEUP), in Portugal, and from the Federal Institution of Paraiba (IFPB), in Brazil.

Victor Hugo C. de Albuquerque acknowledges the sponsorship from the Brazilian National Council for Research and Development (CNPq) through the Grants 470501/2013-8 and 301928/2014-2. 


\section{References}

[1] Martins M, Casteletti LC (2009) Microstructural characterization and corrosion behavior of a super duplex stainless steel casting. Mater Charact 60:150-155.

[2] Badjia R, Bouabdallah M, Bacroix B, Kahloun C, Bettahar K, Kherrouba N. (2008) Effect of solution treatment temperature on the precipitation kinetic of r-phase in 2205 duplex stainless steel welds. Mater Sci Eng A 496(1-2):447-54.

[3] Deng B, Jiang Y, Gong J, Zhong C, Gao J, Li J (2008) Critical pitting and repassivation temperatures for duplex stainless steel in chloride solutions. Electrochim Acta 53(16):5220-5225.

[4] Tavares SSM, Terra VF, Neto PL, Matos DE (2005) Corrosion resistance evaluation of the UNS S31803 duplex stainless steels aged at low temperatures $\left(350-550{ }^{\circ} \mathrm{C}\right)$ using DLEPR tests. J Mater Sci 40(15):40254028.

[5] Jiang ZHL, Chen XY, Huang H, Liu XY (2003) Grain refinement of Cr25Ni5Mo1.5 duplex stainless steel by heat treatment. Mater Sci Eng A 363(1-2):263-267. 
[6] Chen TH, Weng KL, Yang JR (2002) The effect of high temperature exposure on the microstructural stability and toughness property in a 2205 duplex stainless steel. Mater Sci Eng A 338(1-2):259-270.

[7] Pohl M, et al (2007) Effect of intermetallic precipitation on the properties of duplex stainless steel. Mater Character 58:65-71.

[8] Normando PG, Moura EP, Souza JA, Tavares SSM, Padovese LR (2010) Ultrasound, eddy current and magnetic Barkhausen noise as tools for sigma phase detection on a UNS S31803 duplex stainless steel. Mater Sci Eng A 527:2886-2891.

[9] Tavares SSM, Pardal JM, Guerreiro JL, Gomes AM, Da Silva MR (2010) Magnetic detection of sigma phase in duplex stainless steel UNS S31803. J Magn Magn Mater 322(17):L29-L33.

[10] Sieurin H, Sandström R (2007) Sigma phase precipitation in duplex stainless steel 2205. Mater Sci Eng A 444(1-2):271-276.

[11] Souza CM, Abreu HFG, Tavares SSM, Rebello JMA (2008) The $\sigma$ phase formation in annealed UNS S31803 duplex stainless steel: Texture aspects. Mater Charact 59(9):1301-1306.

[12] Sathirachinda N, et al (2009) Depletion effects at phase boundaries in 2205 duplex stainless steel characterized with SKPFM and TEM/EDS. Corros Sci 51:1259-1266. 
[13] Moura VS, Lima LD, Pardal JM, Kina AY, Corte RRA, Tavares SSM (2008) Influence of the microstructure on the corrosion resistance of the duplex stainless steel UNS S31803. Mater Charact 59(8):1127-1132.

[14] Zou D, Han Y, Zhang W, Fan G (2010) Phase transformation and its effects on mechanical properties and pitting corrosion resistance of 2205 duplex stainless steel. J of Iron and Steel Research Inter 17(11):67s-72s.

[15] Wei Z, Laizhu J, Jincheng H, Hongmei S (2009) Effect of ageing on precipitation and impact energy of 2101 economical duplex stainless steel. Mater Charact 6(1);50-55.

[16] Nilssom JO, Kangas P, Karlsson T, Wilson A (2000) Mechanical properties, microstructural stability and kinetics of sigma phase formation in a $29 \mathrm{Cr}-6 \mathrm{Ni}-2 \mathrm{Mo}-0.38 \mathrm{~N}$ super duplex stainless steel. Metall Mater Tran A 31(1):35-45.

[17] Muthupandi V, Srinivasan BP, Seshadri SK, Sundaresan S (2003) Effect of Weld Metal Chemistry and Heat Input on the Structure and Properties of Duplex Stainless Steel Welds. Mater Sci Eng A 58:9-16.

[18] Pardal JM, Tavares SSM, Fonseca MPC, DA Silva MR, M. Ferreira LR (2012) Study of deleterious phase precipitation under continuous cooling of superduplex stainless steel UNS S32750. Mater Sci Tech 28(3):295-302. 
[19] Mohapatra JN, Kamada Y, Kikuchi H, Kobayashi S, Echigoya J, Park DG, Cheong YM (2011) Evaluation of embrittlement in isochronal aged FeCr alloys by magnetic hysteresis loop technique. J Magn 16(2):173-176. [20] Mohapatra JN, Kamada Y, Murakami T, Echigoya J, Kikuchi H, Kobayashi S (2013) Magnetic hysteresis loop technique as a tool for the evaluation of $\sigma$ phase embrittlement in $\mathrm{Fe}-\mathrm{Cr}$ alloys. J Magn Magn Mater $327: 71-75$.

[21] Lo KH, Lai JKL, Shek CH, Li DJ (2007) Magnetic and transformation behaviour of duplex stainless steels under non-isothermal conditions and temperature-fluctuation monitoring. Mater Sci Eng A 452-453:149-160.

[22] Lo KH, Lai JKL (2011) Microstructural characterisation and change in a.c. magnetic susceptibility of duplex stainless steel during spinodal decomposition. J Nucl Mater 401(1-3):143-148.

[23] Ghanei S, Kashefi M, Mazinani M (2013) Eddy current nondestructive evaluation of dual phase steel. Mater Des 50:491-496.

[24] Camerini C, Sacramento R, Areiza MC, Rocha A, Santos R, Rebello JM, Pereira G (2015) Eddy current techniques for super duplex stainless steel characterization. J Magn Magn Mater 388:96-100.

[25] Ghanei S, Kashefi M, Mazinani M (2014) Comparative study of eddy current and Barkhousen noise nondestructive testing methods in 
microstructural examination of ferrita-martensite dual-phase steel. J Magn Magn Mater 356:103-110.

[26] Nunes TM, de Albuquerque VHC, Papa JP, Silva CC, Normando PG, Moura EP, Tavares JMRS (2013) Automatic microstructural characterization and classification using artificial intelligence techniques on ultrasound signals. Expert Syst Appl 40(8):3096-3105.

[27] Albuquerque VHC, Silva EM, Leite JP, Moura EP, de Araújo Freitas VL, Tavares JMRS (2010) Spinodal decomposition mechanism study on the duplex stainless steel UNS S31803 using ultrasonic speed measurements. Mater Des 31(4):2147-2150.

[28] Albuquerque VHC, Silva CC, Normando PG, Moura EP, Tavares JMRS (2012) Thermal aging effects on the microstructure of Nb-bearing nickel based superalloy weld overlays using ultrasound techniques. Mater Des $36: 337-347$.

[29] Silva EM, Albuquerque VHC, Leite JP, Varela ACG, Moura EP, Tavares JMRS (2009) Phase transformations evaluation on a UNS S31803 duplex stainless steel based on nondestructive testing. Mater Sci Eng A 516:126-130.

[30] Albuquerque VHC, Melo TAA, Gomes FORM, Tavares JMRS (2010) Evaluation of grain refiners influence on the mechanical properties in a 
CuAlB shape memory alloy by ultrasonic and mechanical tensile testing. Mater Des 31(7):3275-3281.

[31] Lindgren M, Lepistö T (2004) On the stress vs. Barkhausen noise relation in duplex stainless steel NDT \& Int 37:403-410.

[32] Piotrowski L, Augustyniak B, Chmielewski M, Hristoforou EV, Kosmas K (2010) Evaluation of Barkhausen noise and magneto acoustic emission signals properties for plastically deformed Armco iron. IEEE Trans Magn 46:239-242.

[33] Rebello JMA, Camerini CG, Areiza MCL, Santos RW, Carneval RO (2012) Saturated low frequency eddy current technique applied to phases characterization in duplex stainless steel. Quantitative Non-Destructive Evaluation 311-321.

[34] Uchimoto T., et al (2003) Eddy current evaluation of cast irons for material characterization. J Magn Magn Mater 258:493-496.

[35] Rebello JMA, Sacramento R, Areiza MCL, Assis KS (2010) Quantification of sigma phase precipitation by magnetic nondestructive testing. in: Proceedings of the XV International Workshop on Electromagnetics Non Destructive Evaluation 35:311-321.

[36] Silva EM, Leite JP, França Neto FA, Leite JP, Fialho WML, Albuquerque VHC, Tavares JMRS (2016) Evaluation of the Magnetic 
Permeability for the Microstructural Characterization of a Duplex Stainless Steel. J Test Eval 44(3):20130313.

[37] Freitas VLA, Albuquerque VHC, Silva EM, Silva AA, Tavares JMRS (2010) Nondestructive characterization of microstructures and determination of elastic properties in plain carbon steel using ultrasonic measurements. Mater Sci \& Eng A Structural Materials: properties, microstructure and processing 527:4431-4437.

[38] Albuquerque VHC, Alexandria AR, Cortez PC, Tavares JMRS (2009) Evaluation of Multilayer Perceptron and Self-Organizing Map Neural Network Topologies applied on Microstructure Segmentation from Metallographic Images. NDT \& Inter 42:644-651.

[39] Albuquerque VHC, Rebouças Filho PP, Cavalcante TS, Tavares JMRS (2010). New computational solution to quantify synthetic material porosity from optical microscopic images. Journal of Microscopy 240:50-59. [40] Albuquerque VHC, Tavares JMRS, Cortez PC (2010) Quantification of the microstructures of hypoeutectic white cast iron using mathematical morphology and an artificial neural network. Inter J of Micros Mater Proper 5:52-64.

[41] Albuquerque VHC, Tavares JMRS, Durão LMP (2010) Evaluation of Delamination Damage on Composite Plates using an Artificial Neural 
Network for the Radiographic Image Analysis. Journal of Composite Mater 44:1139-1159.

[42] Albuquerque VHC, Silva CC, Menezes T I S, Farias JP, Tavares JMRS (2011) Automatic evaluation of nickel alloy secondary phases from SEM images. Microscopy Research and Technique 74;36-46.

[43] Albuquerque VHC, Cortez PC, Alexandria AR, Tavares JMRS (2008) A new solution for automatic microstructures analysis from images based on a backpropagation artificial neural network. Nond Test and Eval 23:273-283. [44] Cullity B. D., Graham C. D. (2009) Introduction to Magnetic Materials. 2nd edition. Wiley, New Jersey, USA.

[45] Coey J. M. D. (2009) Magnetism and Magnetic Materials. Cambridge University Press, New York, USA.

[46] Yang M, Chen YC, Chen CH, Huang WP, Lin D-Y (2015) Microstructural characterization of $\delta / \gamma / \sigma / \gamma 2 / \chi$ phases in silver-doped 2205 duplex stainless steel under $800^{\circ} \mathrm{C}$ aging. J Alloys Compd 633:48-53.

[47] Fargas G, Anglada M, Mateo A (2009) Effect of the annealing temperature on the mechanical properties, formability and corrosion resistance of hot-rolled duplex stainless steel. J Mater Process Technol 209(4):1770-1782. 
[48] Martins M, Forti LRN (2008) Effect of aging on impact properties of ASTM A890 Grade 1C super duplex stainless steel. Mater Charact 59(2):162-166. 


\section{FIGURE CAPTIONS}

Figure 1. Experimental setup used: (1) Power supply, (2) Solenoid, (3) Hall sensor, (4) Material sample, (5) Data acquisition board, (6) Computer, (7) Bench test and (8) Potentiometer.

Figure 2. Microstructures of the thermal aged samples at (a) 800 and (c) 900 ${ }^{\circ} \mathrm{C}$ for 2 hours and related X-ray diffractions (c) and (d), respectively.

Figure 3. Amplitude versus external magnetic field for the aging temperatures studied.

Figure 4. Induced magnetic field versus the external one for the temperatures of $700,750,800,850,900$ and $1000{ }^{\circ} \mathrm{C}$ and times up to 2 hours.

Figure 5. Induced magnetic field and Charpy impact energy for the samples aged at (a) 800 and (b) $900{ }^{\circ} \mathrm{C}$.

Figure 6. Fracture surface microstructures of the samples aged at (a) 800 and (b) $900{ }^{\circ} \mathrm{C}$ for $0.25 \mathrm{~h}$.

Figure 7. Induced magnetic field and absorbed energy in terms of the sigma phase percentage.

Figure 8. Influence of the outliers on the induced magnetic field for the aging temperatures of (a) 800 and (b) $900{ }^{\circ} \mathrm{C}$ for $2 \mathrm{~h}$. 


\section{TABLES CAPTION}

Table 1. Conditions of the aging thermal treatments addressed, number of samples studied and tests performed. (The as-received sample was considered as time zero.) 


\section{FIGURES}

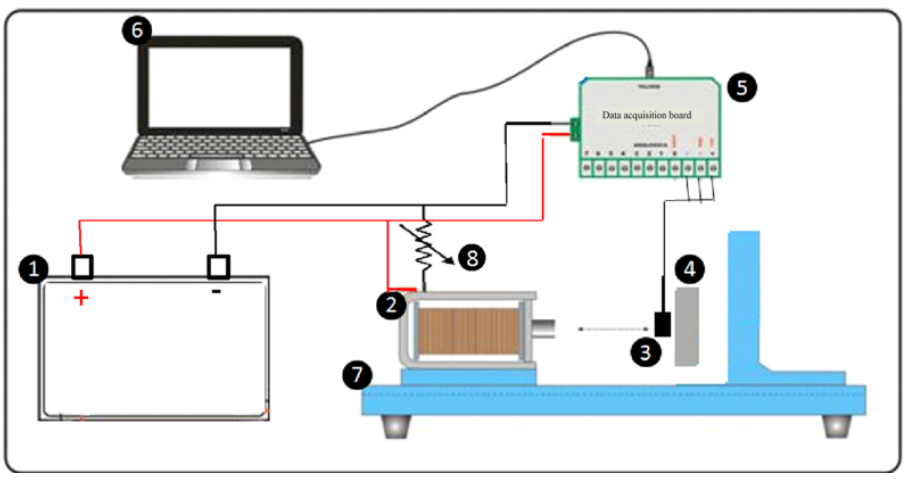

Figure 1

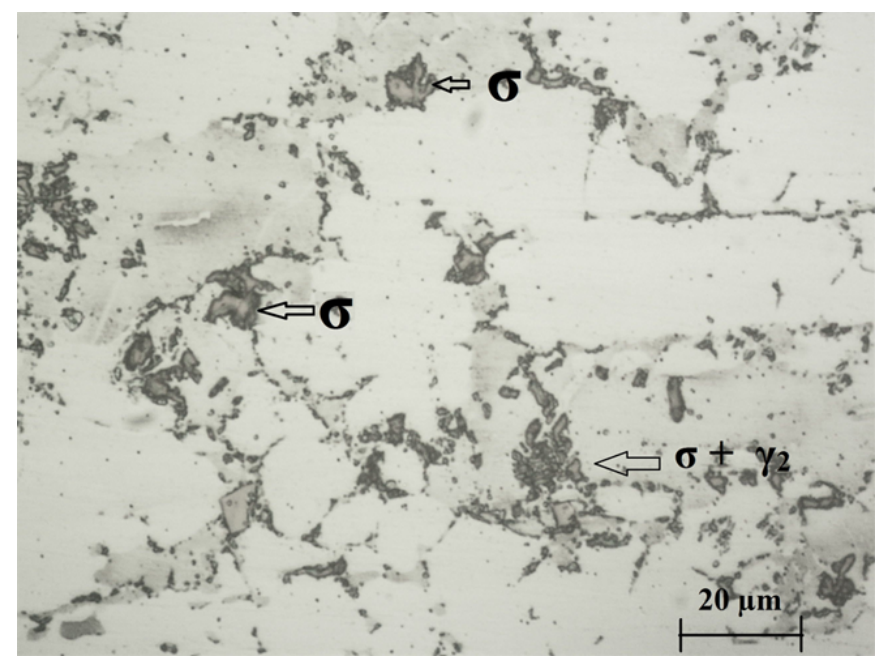

Figure 2a 


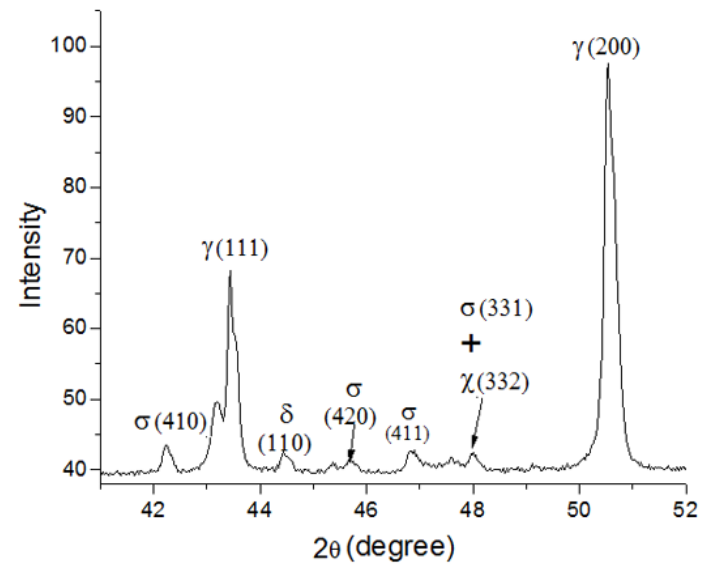

Figure $2 b$

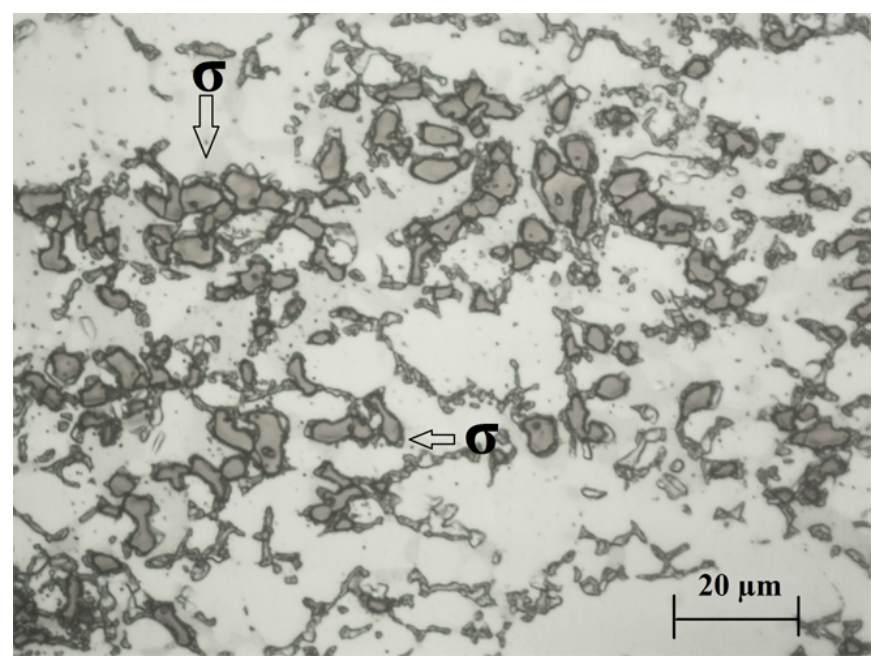

Figure 2c 


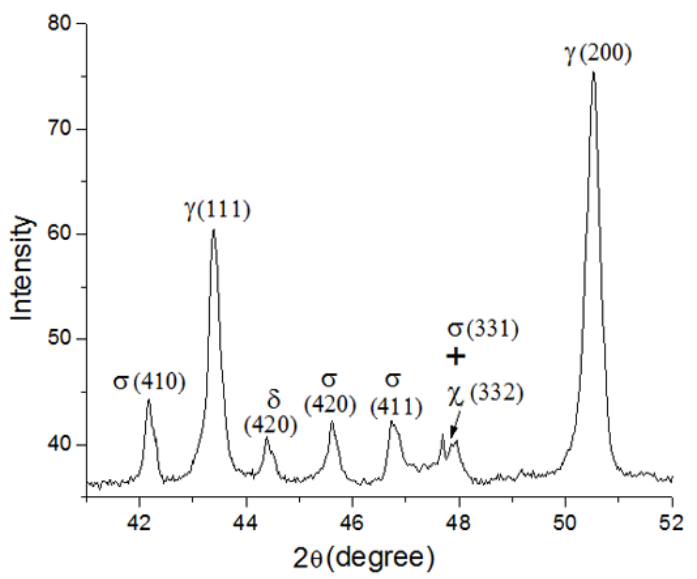

Figure 2d

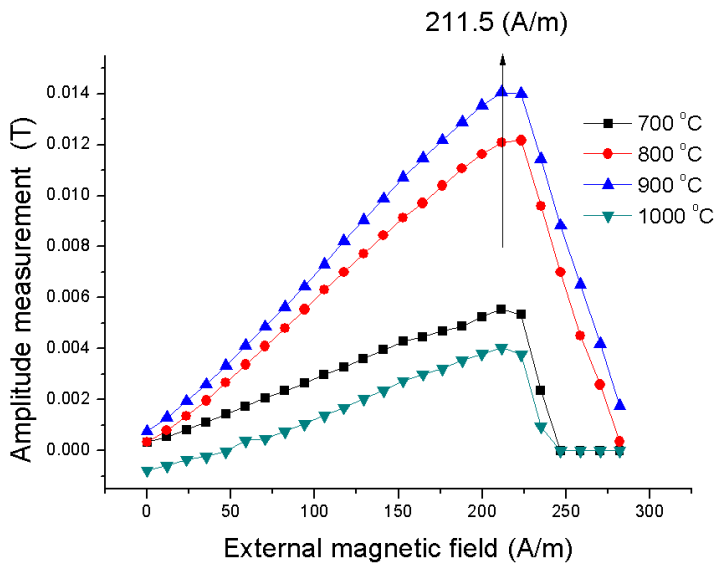

Figure 3

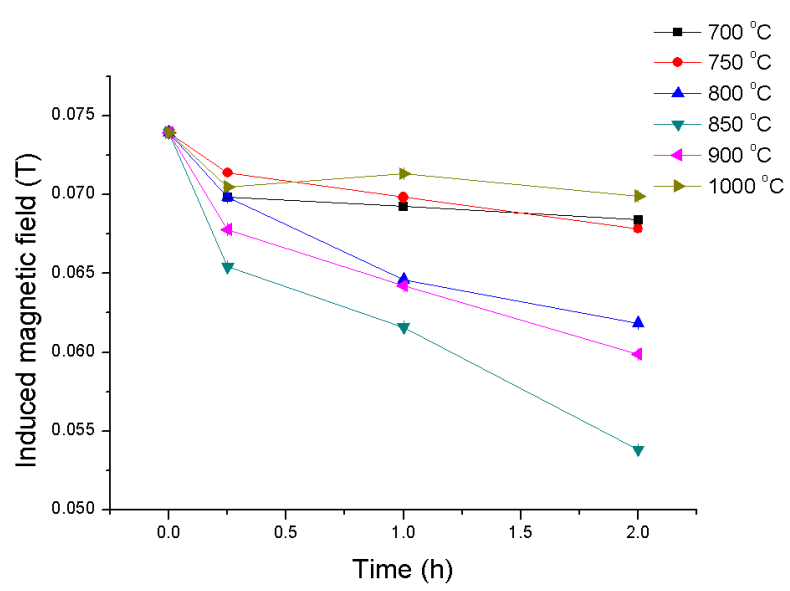

Figure 4 


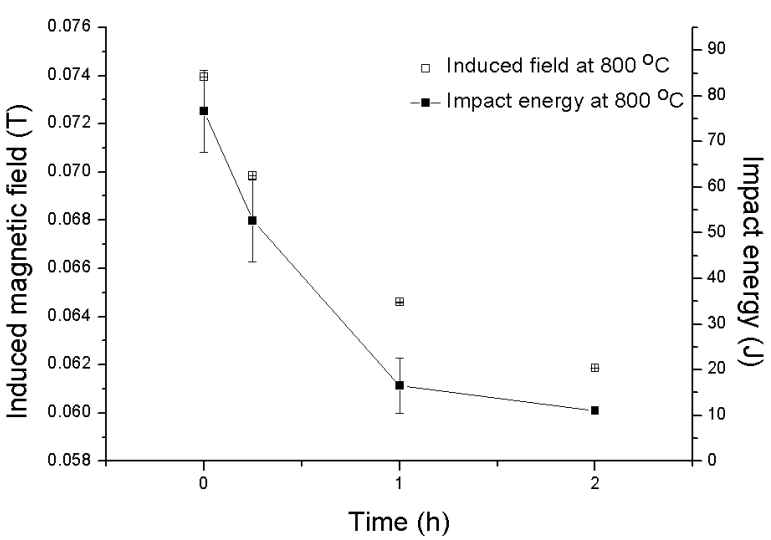

Figure 5a

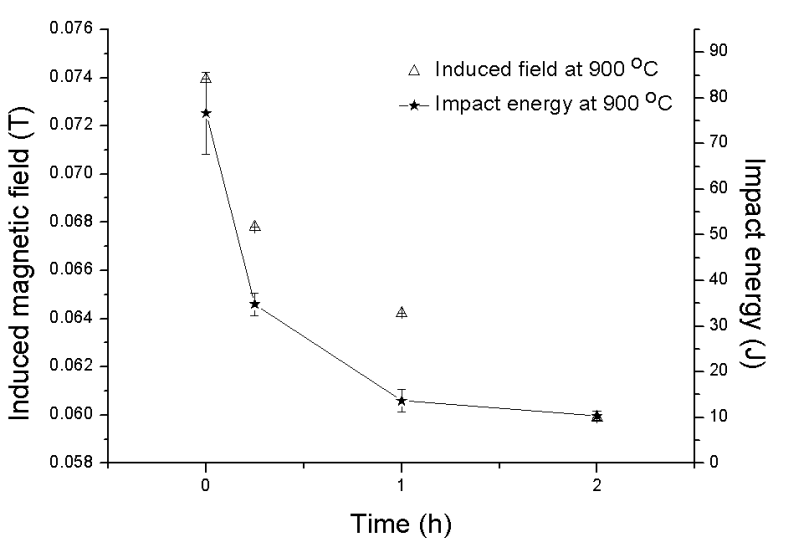

Figure $5 b$

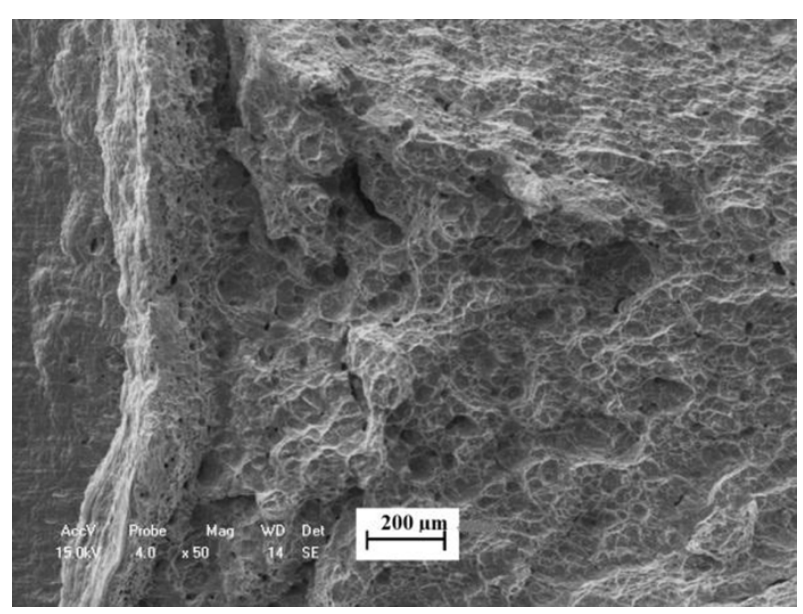

Figure 6a 


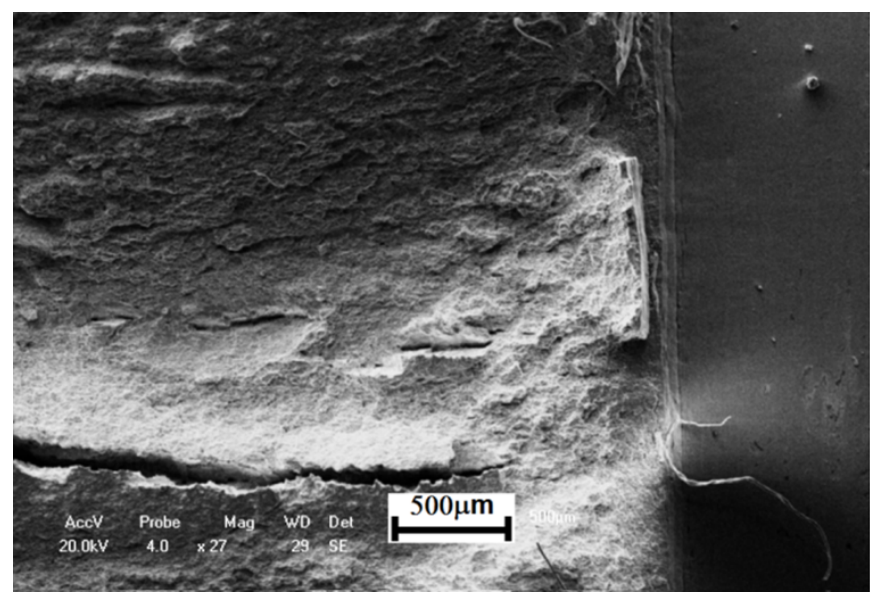

Figure $6 b$

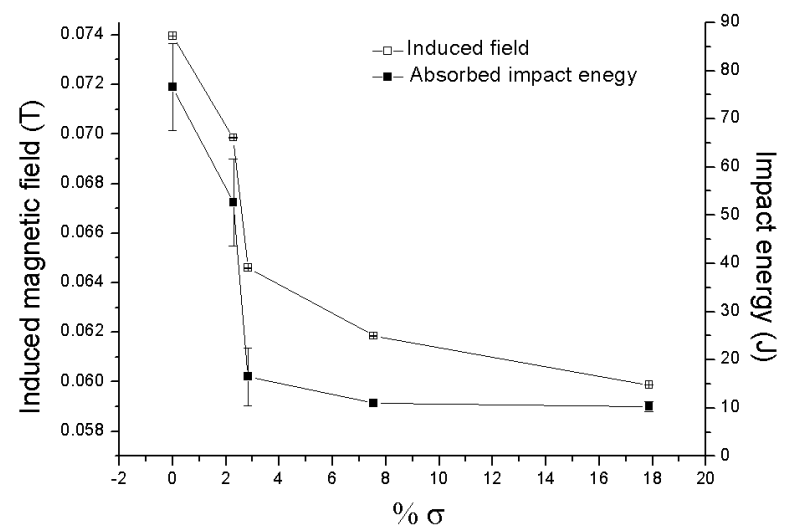

Figure 7

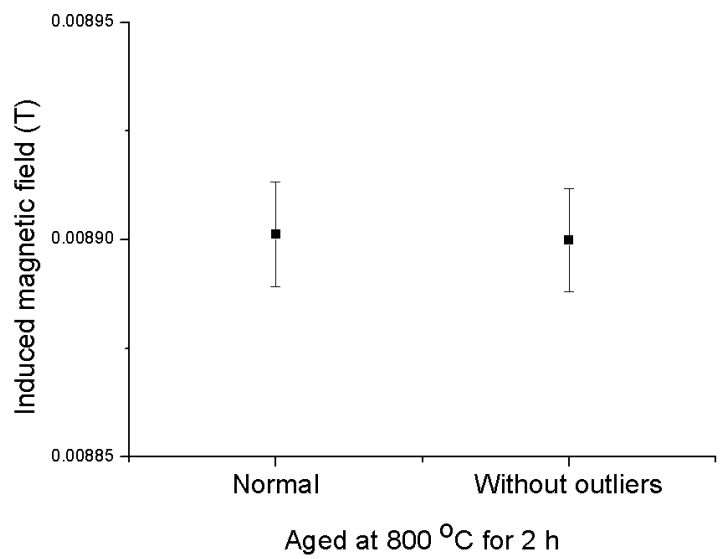

Figure 8a 


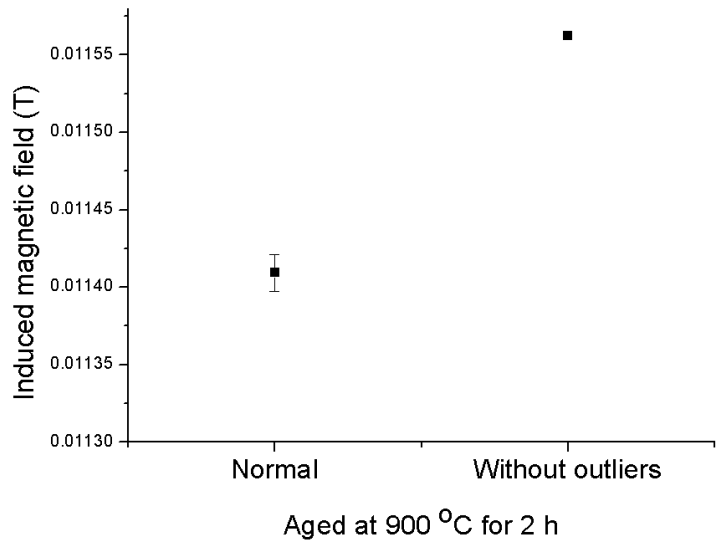

Figure $8 b$ 


\section{TABLES}

Table 1

\begin{tabular}{|c|c|c|c|c|c|}
\hline Temperature $\left({ }^{\circ} \mathrm{C}\right)$ & & Time $(\mathrm{h})$ & & Number of samples & Tests \\
\hline \multirow[t]{4}{*}{ As-received } & \multicolumn{3}{|c|}{0} & 5 & $\mathrm{CI}$ \\
\hline & & & & & $\mathrm{OM}$ \\
\hline & & & & & SEM \\
\hline & & & & & IMFM \\
\hline \multirow[t]{2}{*}{700} & 0.25 & 1 & 2 & 15 & $\mathrm{OM}$ \\
\hline & & & & & IMFM \\
\hline \multirow[t]{2}{*}{750} & 0.25 & 1 & 2 & 15 & $\mathrm{OM}$ \\
\hline & & & & & IMFM \\
\hline \multirow[t]{4}{*}{800} & 0.25 & 1 & 2 & 15 & $\mathrm{CI}$ \\
\hline & & & & & $\mathrm{OM}$ \\
\hline & & & & & SEM \\
\hline & & & & & IMFM \\
\hline \multirow[t]{2}{*}{850} & 0.25 & 1 & 2 & 15 & $\mathrm{OM}$ \\
\hline & & & & & IMFM \\
\hline \multirow[t]{4}{*}{900} & 0.25 & 1 & 2 & 15 & $\mathrm{CI}$ \\
\hline & & & & & $\mathrm{OM}$ \\
\hline & & & & & SEM \\
\hline & & & & & IMFM \\
\hline \multirow[t]{2}{*}{1000} & 0.25 & 1 & 2 & 15 & OM \\
\hline & & & & & IMFM \\
\hline
\end{tabular}

CI - Charpy Impact

MO - Optical Microscopy

SEM - Scanning Electron Microscopy

IMFM - Induced Magnetic Field Measurement 